\title{
Effects of Omega-3 Fatty Acid on Endotoxin-induced Acute Lung Injury in Rabbits
}

\author{
Eun-A Jang*, Sung-Kuk Son ${ }^{*}$, Jeong-Hyeon Kang ${ }^{*}$, Seongheon Lee ${ }^{* *}$ and Sang-Hyun Kwak ${ }^{\dagger, * *}$ \\ Department of Anesthesiology and Pain Medicine Chonnam National University \\ Medical School \& Hospital, Gwangju 61469, Korea
}

\begin{abstract}
This study was undertaken to clarify the effects of omega-3 fatty acid on endotoxin-induced acute lung injury. Rabbits were randomly assigned to one of four groups. Each group received intravenous infusion of saline only, saline and Escherichia coli endotoxin, omegaven infuison $(0.5 \mathrm{~mL} / \mathrm{kg} / \mathrm{hr})$ and endotoxin, lipoven $(0.5 \mathrm{~mL} / \mathrm{kg} / \mathrm{hr})$ and endotoxin respectively. Infusion of saline was started $0.5 \mathrm{hr}$ before the infusion of saline or endotoxin, and omegaven and lipoven were started 2 hours after endotoxin infusion for 4 hours. The lungs of rabbits were ventilated with $40 \%$ oxygen. Mean blood pressure, heart rate, arterial oxygen tension $\left(\mathrm{PaO}_{2}\right)$, and peripheral blood leukocyte were recorded. The wet/dry (W/D) weight ratio of lung and lung injury score were measured, and analysis of bronchoalveolar lavage fluid (BALF) was done. Endotoxin decreased $\mathrm{PaO}_{2}$, and peripheral blood leukocyte and platelet count. And it increased W/D ratio of lung, lung injury score and leukocyte count, percentage of PMN cells, concentration of IL-8 in BALF. Omegaven attenuated all these changes except for peripheral blood leukocyte counts. Omegaven attenuated endotoxin-induced acute lung injury in rabbits mainly by inhibiting neutrophil and IL-8 responses, which may play a central role in endotoxin-related lung injury.
\end{abstract}

Key Words: Acute lung injury, Endotoxins, Systemic inflammatory response syndrome, Omegaven

\section{서 론}

급성 호흡 곤란 증후군은 급성 염증, 미세 혈관 손상 및 증가 된 폐 혈관 및 상피 투과성을 포함하는 복합적 인 임상 증후군이다(Kollef and Schuster, 1995). 치료의 발 달에도 불구하고, 현재도 여전히 $40 \%$ 이상의 높은 사망 률을 보이고 있다(Maca et al., 2017). 급성 호흡 곤란 증후 군의 가장 흔한 원인은 패혈증이라고 알려져 있다(Knaus et al., 1994; Wheeler and Bernard, 2007). 패혈증으로 인한 급 성 호흡 곤란 증후군의 정확한 발병 기전은 아직 밝혀지 지 않았지만, 폐 내 중성구의 과도한 축적, Tumor necrosis factor- $\alpha$ (TNF- $\alpha$ ), Interleukin (IL)-1, IL-6, IL-8 같은 전염증성 사이토카인(Proinflammatory cytokine)의 증가 등이 주요 특 징이며 이러한 매개물들이 급성 호흡 곤란 증후군의 시 작과 진행에 중요한 역할을 한다고 알려져 있다(Jacobs et al., 1989; Suter et al., 1992; Chollet-Martin et al., 1996; Goodman et al., 1996). 폐 내에서의 중성구의 활성화로 인해 미세 혈 관 손상이 일어나고, 중성구 단백분해효소(Protease)와 반 응성 산소종(Reactive oxygen species)이 분비된다(McCord et al., 1994; Okumura et al., 1995). 그 중 IL-8은 항-IL-8 자가 형체의 형성을 통해서 강력하게 호중구 유인 및 활성화 를 시키고, IL-8 복합체는 Fc $\gamma R I I \alpha$ 수용체와의 상호 작용 을 통해 급성 폐 손상의 발생에 중요한 역할을 한다(Allen

Received: December 12, 2020 / Revised: March 2, 2021 / Accepted: March 3, 2021

*Post-Doctor, ${ }^{* *}$ Professor.

${ }^{\dagger}$ Corresponding author: Sang-Hyun Kwak. Department of Anesthesiology and Pain Medicine Chonnam National University Medical School \& Hospital, 42 Jebong Ro, Donggu, Gwangju 61469, Korea.

Tel: +82-62-220-6893, Fax:+82-62-232-6294, e-mail: shkwak@jnu.ac.kr

(C) The Korean Society for Biomedical Laboratory Sciences. All rights reserved.

(c) This is an Open Access article distributed under the terms of the Creative Commons Attribution Non-Commercial License (http://creativecommons.org/licenses/by-nc/3.0/) which permits unrestricted non-commercial use, distribution, and reproduction in any medium, provided the original work is properly cited. 
and Kurdowska, 2014).

Eicosapentaenoic acid (EPA), Docosahexaenoic acid (DHA), $\alpha$-linolenic acid (ALA) 등의 오메가-3 지방산은 다가의 불 포화 지방산으로 인체에 유용한 다양한 효과가 밝혀져 있 다. 그 효과를 살펴보면, 중성지방을 줄이고, High density lipoprotein (HDL) 콜레스테롤을 증가시켜 고지혈증을 예 방하고(Maki et al., 2013), 전신 혈관 저항을 감소시켜 혈 압을 낮추며(Miller et al., 2014), 허혈성 항 부정맥 효과 (Pignier et al., 2007), 관상 동맥 심장 질환 환자의 심근 경 색 및 심장 질환으로 인한 사망을 감소시키는(Bucher et al., 2002) 등의 효과를 나타내었다. 유방암, 대장암, 전립선암 에 대한 항암 효과 및(de Deckere, 1999; Augustsson et al., $2003)$ 우울증, 불안, 파킨슨병 같은 정신 질환에 대한 효 과가 밝혀져 있다(Naliwaiko et al., 2004; Green et al., 2006; Bousquet et al., 2008). 또한 류마티스 관절염 같은 만성 염증에도 항염증 효과가 있다고 밝혀져 있다(Fortin et al., 1995).

오메가-3의 이러한 효과들 중 항염증 효과는 다양한 메 커니즘에 의해 나타나며 이러한 작용들은 세포막의 지방 산 구성의 변화와 관련이 있다. 세포막의 구성물의 변화 는 세포막의 유동성, 변경된 유전자 발현으로 이어지는 세포 신호 전달 체계, 지질 매개체 생산 등을 조정할 수 있다(Calder, 2010). 항염증 작용에 대한 다양한 오메가-3 작용 중 염증 부위에서 방출되는 화학물질에 반응하여 백 혈구가 염증 활성화 부위로 이동하는 과정인 백혈구의 주 화성(Chemotaxis)과 유사한 성향의 작용이 있다(Lewis et al., 1990; Schmidt et al., 1991). 이때 염증 부위에서 방출되는 화학물질을 화학유인물질(chemo-attractants)이라 이름 부르 며, Arachidonic acid에서 파생되는 Leukotriene B4가 포함된 다. 그 기전이 아직은 명확하진 않으나 화학유인물질와 관련된 수용체에 대한 길항 작용 또는 발현감소에 영향 을 미칠 것으로 예측되기에(Lewis et al., 1990; Schmidt et al., 1991; Sperling et al., 1993; Calder, 2013), 우리는 Endotoxin으 로 유발된 급성 폐 손상에 오메가-3 지방산이 풍부한 지 방 유제인 Omegaven의 화학유인물질과 관련된 항염증 효과를 알아보고자 하였다.

\section{대상 및 방법}

\section{실험 동물}

2.0 2.5 kg의 수컷 백색 토끼(Damul science, 대전)를 사 용하였다. 실험 동물은 음식과 물에 자유롭게 접근할 수
있었으며, 12 시간의 낮과 밤의 순환을 유지하였다. 모든 실험은 임상연구심의 위원회의 승인 후(CNU-IACUC-H2015-27) 시행되었다.

\section{실험 방법}

먼저 실험 동물들을 Ketamine hydrochloride $(30 \mathrm{mg} / \mathrm{kg})$ 과 Xylazin hydrochloride $(0.3 \mathrm{mg} / \mathrm{kg})$ 으로 마취한 후 수액과 약물의 지속적 주입을 위해 귀의 이 정맥에 카테터를 삽 입하였다. 이 정맥관을 통해 실험이 끝날 때까지 Lactated Ringer's solution을 $8 \mathrm{~mL} / \mathrm{kg} / \mathrm{hr}$ 의 속도로 투여하였다. 자발 호흡 상태에서 기관절개(tracheostomy)를 무균적으로 시행 후 기관 내 삽관하였고(3.5-mm 커프 없는 튜브), 마취의 유지와 근 이완을 위해 Ketamine $(3 \mathrm{mg} / \mathrm{kg} / \mathrm{hr}$ )과 Vecuronium bromide $(0.05 \mathrm{mg} / \mathrm{kg} / \mathrm{hr})$ 를 지속 주입하였다. 기계 환기기 (Servo 900B, Siemen-Elema, Solna, Sweden)를 이용하여 실험 동물의 폐를 기계 환기하였다(흡기압 $15 \mathrm{cmH}_{2} \mathrm{O}$, 호기말 양압 $3 \mathrm{cmH}_{2} \mathrm{O}$, 산소 농도 $40 \%$, I:E ratio 1:2) 호흡수는 이 산화탄소분압 $\left(\mathrm{PaCO}_{2}\right)$ 이 $35 \sim 50 \mathrm{mmHg}$ 으로 유지되도록 조 절하였다.

실험 동물의 체온유지를 위해 식도 온도를 $36.5^{\circ} \mathrm{C}$ 에서 $37.5^{\circ} \mathrm{C}$ 로 유지하도록 전기 담요에 누이고, 가열 등으로 비 춰주었다. 지속적인 동맥압의 감시와 동맥혈 검사를 위해 경동맥을 통해 대동맥으로 카테터를 삽입하였다.

기초값 측정 후, 실험 동물을 무작위로 네 그룹으로 나 누었다; 첫 번째는 Saline만 투여한 S-S 그룹 $(\mathrm{n}=7)$, 두 번 째는 30 분간 Saline 투여 후, 30 분간 Escherichia coli endotoxin 0111:B4 (from Sigma Chem Co., St. Louis, Mo, U.S.A.) 을 $5 \mathrm{mg} / \mathrm{kg}$ 으로 투여한 S-E 그룹(n=7), 세 번째는 30분간 식염수 투여 후, Endotoxin을 30분간 투여한 후, Endotoxin 투여 시작 시점으로부터 2시간째부터 오메가-3 지방산이 풍부한 Omegaven을 $0.5 \mathrm{~mL} / \mathrm{kg} / \mathrm{hr}$ 로 4시간 동안 투여한 $\mathrm{E}-\mathrm{O}$ 그룹 $(\mathrm{n}=7)$, 마지막 네 번째는 Endotoxin 투여 2시간 째부터 오메가-6 지방산이 풍부한 Lipoven을 $0.5 \mathrm{~mL} / \mathrm{kg} / \mathrm{hr}$ 로 4시간 동안 투여한 E-L 그룹 $(\mathrm{n}=7)$ 으로 나누었다. S-S 그룹과 S-E 그룹은 Lipoven과 Omegaven 같은 용량의 Saline을 투여하였다. 모든 그룹은 Endotoxin 투여 시점부 터 6시간까지 Saline이나 실험약물을 투여하였다(Fig. 1).

동맥혈 가스 분석과 백혈구와 혈소판수의 측정을 위해 Saline나 Endotoxin 투여 30분 전, 투여 시, 투여 후 1, 2, 3, $4,5,6$ 시간에 동맥혈 채취를 시행하였다. Saline나 Endotoxin 투여 6시간 후 실험 동물들은 치오펜탈 과량 투여로 희 생시켰다. 그 직후 토끼의 흉곽을 열어서 폐를 일괄적으 


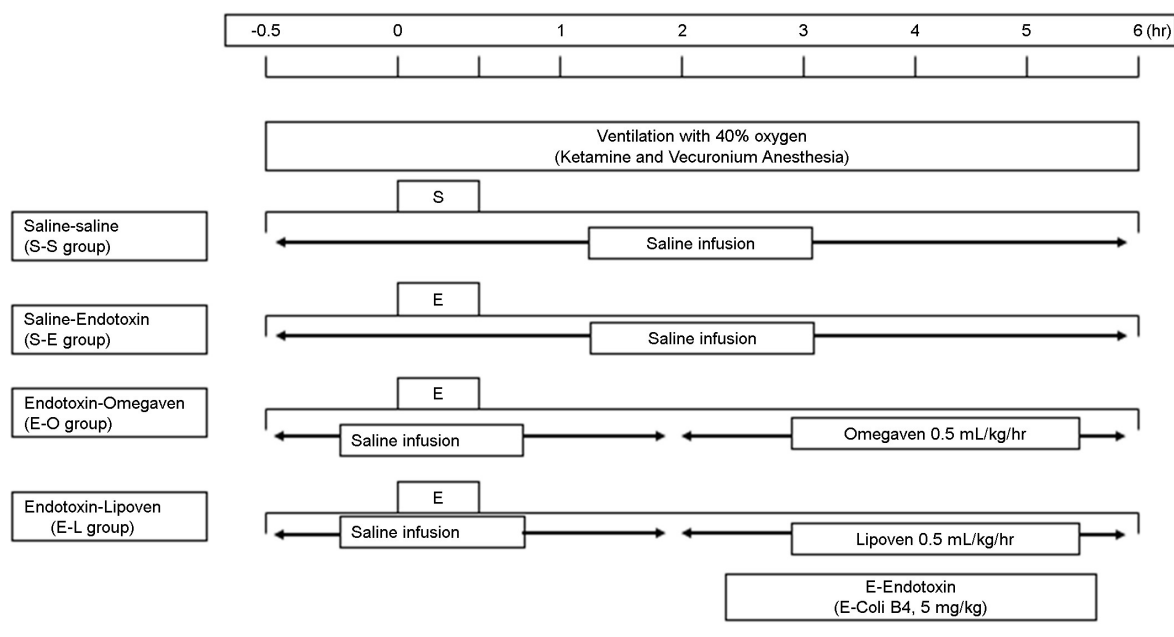

Fig. 1. Experimental group design. Each group received saline infusion for the first 30 minutes. S-S group received saline only throughout the study. S-E group received endotoxin for 30 minutes before and after saline infusion. E-O group and E-L group received Omegaven and Lipoven for 4 hours, respectively (S-S: Saline; SE: Saline-endotoxin; E-O: EndotoxinOmegaven; E-L: Endotoxin-Lipoven).
로 제거하여 좌측 폐 상엽은 wet-dry weight ratio를 측정하 고, 좌측 폐 하엽은 폐 손상 점수(lung injury score), 우측 폐는 기관지폐포세척액(Bronchoalveolar lavage fluid, BALF) 의 백혈구수와 다핵호중구의 백분율, IL-8의 농도를 측정 하였다.

\section{동맥혈 가스 분석 및 말초혈액 세포수 분석}

동맥혈은 혈액 가스 분석기(GEM Premier Plus, Instrumentation Laboratory, Lexington, MA, U.S.A.)를 이용하여 동맥 혈산소분압 $\left(\mathrm{PaO}_{2}\right)$, 이산화탄소분압 $\left(\mathrm{PaCO}_{2}\right), \mathrm{pH}$, 염기과잉 (Base excess)을 분석하였다. 말초혈액 백혈구수는 세포수 분석기(XE2100, Sysmex, Kobe, Japan)로 측정하였다.

\section{Lung wet/dry weight (W/D) ratio}

좌폐상엽의 무게를 잰 다음 $60^{\circ} \mathrm{C}$ 오븐에서 48 시간 동 안 건조시킨 후 무게를 측정하였다. 조직의 부종 정도를 평가하기 위해 wet/dry weight ratio를 계산하였다.

\section{조직학적 검사}

조직의 고정을 위해 왼아래기관지를 통하여 $10 \% \mathrm{Glu}-$ taraldehyde solution를 좌하엽에 점적주입한 후 파라핀에 함몰시켰다. 고정된 후 잘라낸 절편은 Hematoxylin과 Eosin 으로 염색하였다. 실험에 대해 모르는 두 명의 관찰자가 광현미경으로 절편을 관찰한 후 폐포의 울혈, 출혈, 부종, 공기층과 혈관벽에 호중구의 침윤과 응집정도, 폐포벽의 두께와 유리질막 형성 등을 종합 평가하여, 손상의 정도 를 0(손상없음)부터 4(최대 손상)까지 점수를 매겼다.

\section{기관지폐포세척액(bronchoalveolar lavage fluid, BALF) 의 수집}

우측 폐에서 $\mathrm{BALF}$ 를 수집하였다. 우측 기관지를 통해 $35 \mathrm{~mL}$ 의 식염수를 다섯 차례에 걸쳐 천천히 주입하고 회 수하기를 반복하였다. 식염수는 Ethylendiamine tetraacetic acid (EDTA)-2Na를 포함하고 있었으며, 백혈구의 대사를 막기 위해 $4{ }^{\circ} \mathrm{C}$ 로 냉각시켰다. BALF로 세포수와 세포분화 를 분석하였다.

$\mathrm{BALF}$ 를 원심분리하여 세포분화 측정을 위해 WrightGiemsa 염색을 시행하였다. 세포수 분석기(cell counter, XE2100, Sysmex, Kobe, Japan)로 BALF의 백혈구수를 계산 하였다. BALF의 세포를 제거하기 위해 $4{ }^{\circ} \mathrm{C}$ 에서 20 분간 원심분리하였다. 세포가 없는 상층액은 여러 부분으로 나 누어졌으며 변수 값들의 측정을 위해 $-80^{\circ} \mathrm{C}$ 에서 보관하 였다.

\section{기관지폐포세척액(bronchoalveolar lavage fluid, BALF) 에서의 $\mathrm{IL}-8$ 측정}

IL-8의 농도는 효소면역측정법(ELISA, Amersham, Bucks, U.K.)으로 측정하였다.

\section{통계}

폐 손상 점수는 중앙값으로 표현하고 나머지 데이터는 평균값 \pm 표준편차로 표시하였다. 데이터 값들의 분석은 다중비교를 이용하였다. 여러 시간에 대해 측정한 데이 터 값들에 대해서는 ANOVA 검정 후 Dunnett의 검정을 이용하였으며, 단일 시간에 대해 측정한 값에 대해서는 
Table 1. Changes in blood gas, hemodynamics and peripheral blood leukocytes

\begin{tabular}{|c|c|c|c|c|c|c|c|c|}
\hline \multirow{2}{*}{ Variables } & \multicolumn{8}{|c|}{ Time after start of endotoxin or saline infusion } \\
\hline & -0.5 & 0 & 1 & 2 & 3 & 4 & 5 & 6 \\
\hline \multicolumn{9}{|c|}{$\mathrm{PaCO}_{2}(\mathrm{mmHg})$} \\
\hline S-S & $37 \pm 0.7$ & $35 \pm 1$ & $35 \pm 1.2$ & $34 \pm 2$ & $35 \pm 2.4$ & $35 \pm 1.7$ & $33 \pm 1.1$ & $33 \pm 1.1$ \\
\hline S-E & $37 \pm 0.7$ & $41 \pm 2.3$ & $41 \pm 3.1$ & $49 \pm 6.5$ & $50 \pm 6.7$ & $51 \pm 7.1$ & $52 \pm 6.2$ & $56 \pm 7$ \\
\hline E-O & $39 \pm 1.1$ & $42 \pm 2.2$ & $39 \pm 3.0$ & $38 \pm 3.3$ & $43 \pm 3.8$ & $41 \pm 3.1$ & $44 \pm 3.7$ & $45 \pm 3.3$ \\
\hline E-L & $41 \pm 0.9$ & $39 \pm 2.6$ & $38 \pm 3.2$ & $41 \pm 4.3$ & $39 \pm 4.5$ & $39 \pm 3.2$ & $39 \pm 4.1$ & $42 \pm 3.7$ \\
\hline \multicolumn{9}{|l|}{ HR (bpm) } \\
\hline S-S & $222 \pm 3$ & $222 \pm 3$ & $224 \pm 2$ & $226 \pm 3$ & $224 \pm 2$ & $224 \pm 2$ & $220 \pm 4.1$ & $225 \pm 2$ \\
\hline S-E & $225 \pm 4$ & $225 \pm 4$ & $212 \pm 11$ & $221 \pm 6$ & $214 \pm 8$ & $207 \pm 8$ & $203 \pm 10$ & $201 \pm 13$ \\
\hline E-O & $224 \pm 9$ & $232 \pm 5$ & $222 \pm 9$ & $233 \pm 7$ & $221 \pm 7$ & $219 \pm 7$ & $211 \pm 9$ & $199 \pm 6$ \\
\hline E-L & $228 \pm 9$ & $231 \pm 7$ & $224 \pm 6$ & $220 \pm 10$ & $237 \pm 6$ & $232 \pm 10$ & $221 \pm 10$ & $224 \pm 11$ \\
\hline \multicolumn{9}{|c|}{ MBP (mmHg) } \\
\hline S-S & $84 \pm 3$ & $82 \pm 3$ & $85 \pm 4$ & $89 \pm 3$ & $88 \pm 4$ & $86 \pm 3$ & $85 \pm 4$ & $85 \pm 3$ \\
\hline S-E & $78 \pm 4$ & $77 \pm 6$ & $78 \pm 5$ & $78 \pm 6$ & $83 \pm 5$ & $82 \pm 5$ & $77 \pm 7$ & $87 \pm 7$ \\
\hline E-O & $73 \pm 4$ & $84 \pm 4$ & $82 \pm 5$ & $86 \pm 4$ & $76 \pm 7$ & $76 \pm 7$ & $72 \pm 7$ & $76 \pm 8$ \\
\hline E-L & $77 \pm 4$ & $85 \pm 4$ & $81 \pm 6$ & $83 \pm 6$ & $78 \pm 4$ & $80 \pm 5$ & $73 \pm 7$ & $74 \pm 8$ \\
\hline \multicolumn{9}{|c|}{$\mathrm{WBC}\left(10^{2} / \mathrm{mm}^{3}\right)$} \\
\hline S-S & $44 \pm 2$ & $47 \pm 2$ & $44 \pm 4$ & $48 \pm 4$ & $49 \pm 4$ & $48 \pm 5$ & $44 \pm 3$ & $45 \pm 2$ \\
\hline S-E & $52 \pm 6$ & $50 \pm 6$ & $26 \pm 5^{* \dagger}$ & $20 \pm 3^{* \dagger}$ & $16 \pm 2^{* \dagger}$ & $14 \pm 2^{* \dagger}$ & $13 \pm 2^{* \dagger}$ & $14 \pm 2^{* \dagger}$ \\
\hline E-O & $47 \pm 4$ & $46 \pm 4$ & $23 \pm 2^{* \dagger}$ & $18 \pm 3^{* \dagger}$ & $15 \pm 2^{* \dagger}$ & $12 \pm 1^{* \dagger}$ & $12 \pm 1^{* \dagger}$ & $12 \pm 1^{* \dagger}$ \\
\hline E-L & $52 \pm 7$ & $49 \pm 6$ & $27 \pm 5^{* \dagger}$ & $19 \pm 3^{* \dagger}$ & $15 \pm 2^{* \dagger}$ & $13 \pm 2^{* \dagger}$ & $11 \pm 1^{* \dagger}$ & $11 \pm 2^{* \dagger}$ \\
\hline
\end{tabular}

$* P<0.05$ vs. values of time 0 within group, $\uparrow P<0.05$ vs. S-S group (S-S: Saline; S-E: Saline-endotoxin; E-O: Endotoxin-Omegaven; E-L: Endotoxin-Lipoven)

Student's unpaired $t$ 검정을 이용하였다. 조직학적 데이터에 는 Wilcoxon $U$-test를 이용하였다. $P$ value 값이 0.05 미만인 경우 의미 있는 결과값이라 판단하였다.

\section{결 과}

심박수와 평균혈압의 혈류역학은 모든 그룹에서 통계 적 유의한 차이를 보이지 않았다. 동맥혈 내의 이산화탄 소분압은 S-E, E-O, E-L 그룹에서 S-S 그룹에 비해 증가하 였다. 말초 백혈구수는 S-S 그룹과 비교해서 S-E, E-O, E-L 그룹에서 점차적으로 감소하였다(Table 1). 동맥혈산소분 압은 S-E 그룹은 S-S 그룹과 비교하여 점차적으로 감소 하는 양상을 보였으며, Omegaven은 동맥혈산소분압의 감 소를 유의하게 감소시켰다(Fig. 2).

Wet/dry weight ratio는 S-S 그룹과 비교하여 S-E 그룹에 서 증가하였고, Omegaven은 그 증가 정도를 유의하게 감 소시켰다(Fig. 3).

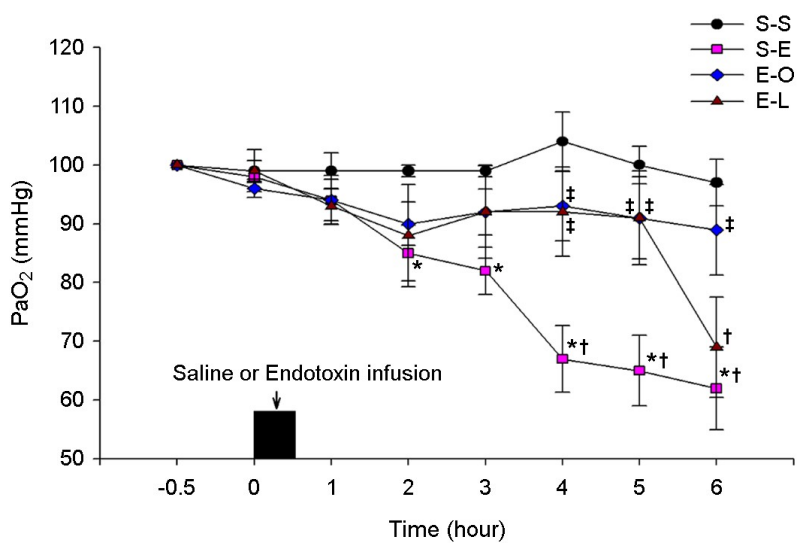

Fig. 2. Partial pressure ofarterial oxygen $\left(\mathrm{PaO}_{2}\right)$ changes in each study group. $\mathrm{PaO}_{2}$ decrease gradually in S-E group, compared with $\mathrm{S}-\mathrm{S}$ group. Omegaven attenuate the decrease in the $\mathrm{PaO}_{2}$. $* P<$ 0.05 vs. values of time 0 within group, $\uparrow P<0.05$ vs. group S-S, $\$ P<0.05$ vs. group S-E (S-S: Saline; S-E: Saline-endotoxin; E-O: Endotoxin-Omegaven; E-L: Endotoxin-Lipoven). 


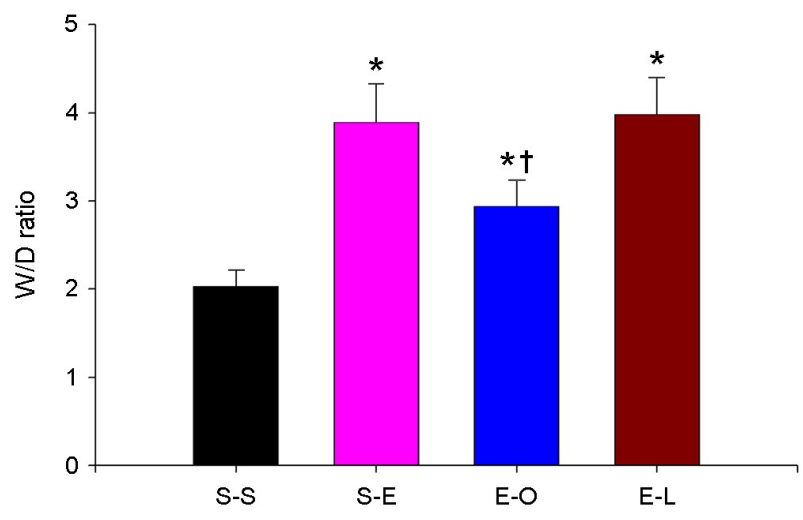

Fig. 3. Comparison of wet/dry weight ratio. The wet/dry weight ratio increase in S-E group, compared with S-S group. Omegaven attenuate the increase in this ratio. ${ }^{*} P<0.05$ vs. S-S group, $\uparrow P<0.05$ vs. S-E group (S-S: Saline; S-E: Saline-endotoxin; E-O: EndotoxinOmegaven; E-L: Endotoxin-Lipoven).

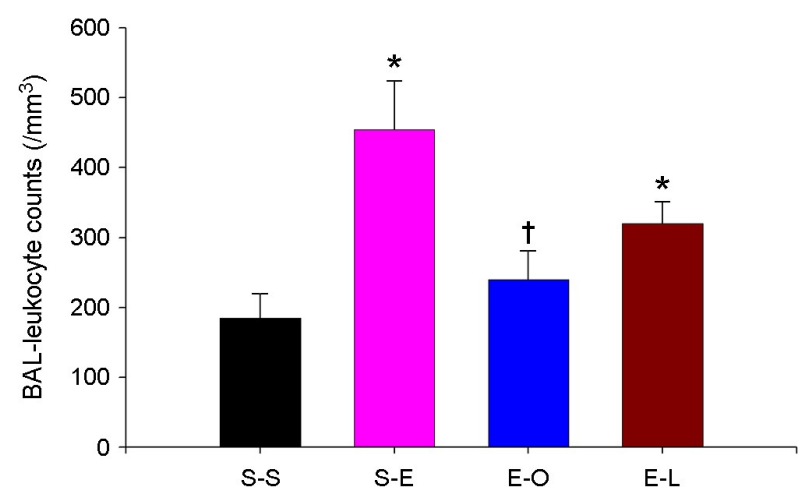

Fig. 4. Comparison of leukocyte counts in BALF. The leukocyte counts in BALF increase in S-E group, compared with S-S group. Omegaven attenuate the increase in leukocyte counts in BALF. $* P$ $<0.05$ vs. S-S group, $\uparrow P<0.05$ vs. S-E group (S-S: Saline; S-E: Saline-endotoxin; E-O: Endotoxin-Omegaven; E-L: EndotoxinLipoven)

BALF의 성분분석 결과를 보면 S-S 그룹과 비교하여 S-E 그룹에서 백혈구의 수가 증가하였고, 이는 말초혈액 에서 폐포 내로 백혈구의 이동을 의미하는데 Omegaven 은 이 증가 정도를 유의하게 감소시켰다(Fig. 4). 또한 S-S 그룹과 비교하여 S-E 그룹에서 다핵호중구의 백분율이 증 가하였는데, Omegaven은 이 증가량을 유의하게 감소시켰 다(Fig. 5).

$\mathrm{S}-\mathrm{S}$ 그룹과 비교하여 S-E 그룹에서 IL-8의 농도가 증가 하였고, Omegaven은 이 증가량을 유의하게 감소시켰다 (Fig. 6).

절편의 광학현미경 사진을 비교해보면, S-E 그룹에서

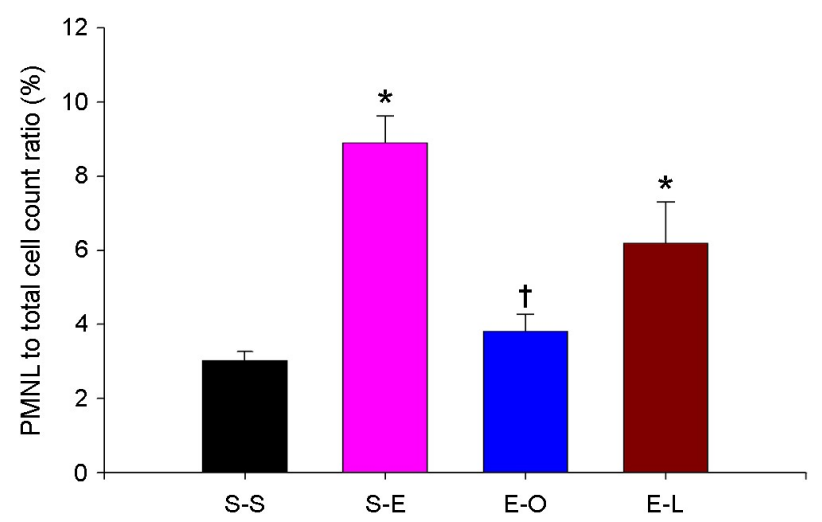

Fig. 5. Comparison of the percentage of PMNL in BLAF. The percentage of polymorphonuclear neutrophils in the BALF markedly increases in S-E group, compared with S-S group. Omegaven attenuate the increase. ${ }^{*} P<0.05$ vs. S-S group, $\uparrow P<0.05$ vs. S-E group (S-S: Saline; S-E Saline-endotoxin; E-O: Endotoxin-Omegaven; E-L: Endotoxin-Lipoven).

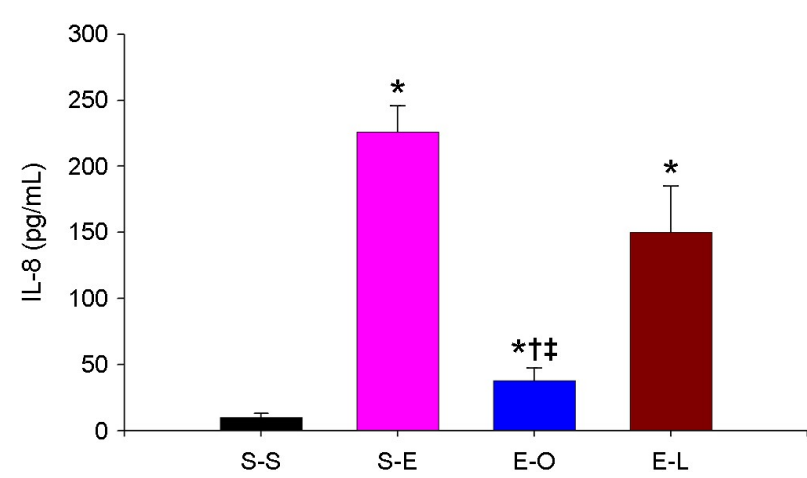

Fig. 6. Comparison of the concentration of IL-8 in BALF. The concentration of IL-8 in the BALF increase in S-E group, compared with S-S group. Omegaven attenuate the increase. ${ }^{*} P<0.05$ vs. SS group, $\uparrow P<0.05$ vs. S-E group, $\downarrow P<0.05$ vs. E-L group (S-S: Saline; S-E: Saline-endotoxin; E-O: Endotoxin-Omegaven; E-L: Endotoxin-Lipoven).

부종과 출혈, 폐포벽의 비후, 폐포 공간으로의 염증 세포 의 침윤이 관찰되었고, E-O 그룹에서 이러한 변화의 정도 가 줄어들었음을 알 수 있었으며, 폐 손상 점수를 비교하 였을 때도 Omegaven은 폐의 손상을 줄여주었음을 알 수 있다(Fig. 7).

이상으로 봤을 때 Omegaven은 폐 손상과 연관된 패혈 증의 핵심역할을 한다고 알려진 백혈구와 전염증성 사이 토카인인 IL-8을 부분적으로 줄여줌으로써 내독소에 의한 급성 폐 손상을 줄여준다고 생각된다. 

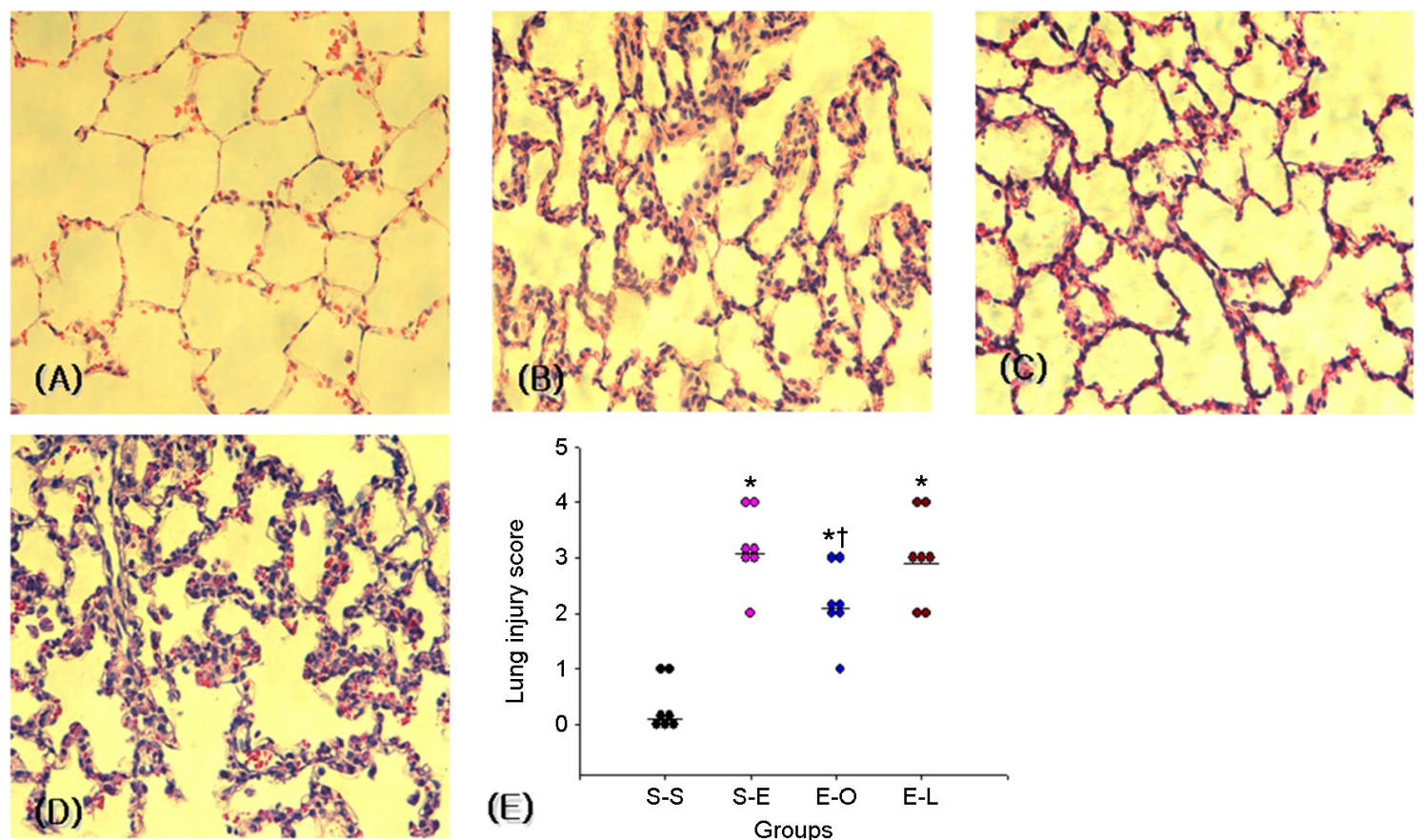

Fig. 7. Photomicrographic views of median value of lung injury score in (A) S-S group, (B) S-E group, (C) E-O group, (D) E-L group \& (E) lung injury score. Light microscopic findings in S-E group include edema, hemorrhage, thickening of the alveolar wall, and infiltration of inflammatory cells into alveolar spaces. In contrast, these changes were less prominent in the rabbits receiving omegaven. Assessment of the lung injury scores demonstrated that omegaven successfully reduced the histopathologic severity of the lung injury (S-S: Saline; SE: Saline-endotoxin; E-O: Endotoxin-Omegaven; E-L: Endotoxin-Lipoven).

\section{고 찰}

본 실험의 주요한 결과는 Omegaven이 Endotoxin으로 유도된 폐 손상(산소화 악화, W/D 무게 비율, 폐 손상 점 수) 정도를 감소 시켰고, 또한 Endotoxin으로 인한 염증성 사이토카인(IL-8)과 호중구 반응을 억제하였다.

Endotoxin으로 유도 급성 폐 손상으로 인한 급성 호흡 곤란 증후군은 호중구 축적, 간질 부종, 상피 무결성의 파 괴 및 폐포 공간으로의 단백질 누출과 그에 따른 가스 교 환의 심각한 변화를 초래하는 복잡한 증후군이다(Kollef and Schuster, 1995).

호중구, 사이토카인/케모카인, 지질 매개체(Phospholipase A2, Thromboxane A2, Prostacyclin) 및 혈소판 활성화 인자를 포함한 다양한 염증성 매개체들이 ARDS 환자의 혈액과 BALF에서 발견 되었다(Demling, 1993; Touqui and Arbibe, 1999). 이들 매개체들은 급성 폐 손상 및 $\mathrm{ARDS}$ 의 시작 및 진행에 중요한 역할을 한다.

Endotoxin은 TNF- $\alpha$, IL-1, IL-6 및 IL-8과 같은 사이토카 인을 방출하는 폐포 대식 세포의 활성화를 유발한다. 이
물질들은 내피막에서 접착 분자의 발현을 향상시켜 폐 혈관 내피에 대한 호중구의 화학 주성과 부착을 촉진한 다(Brigham and Meyrick, 1986; Bernard and Tedgui, 1992). 이 는 보체계를 활성화 시켜 화학 주성 효과와 중성구의 축 적을 가속화 한다.

부착 분자를 통해 폐 혈관 내피에 부착된 활성화 된 호중구는 프로테아제(Protease), 반응성 산소종(Reactive oxygen species) 및 아라키돈 산 대사 산물(특히 TxA2)을 방출함으로써 내피를 공격한다. 이 물질들은 기관지 수축 과 폐 혈관 수축을 매개하고 폐 부종을 일으키는 모세 혈관 투과성을 증가시킨다. 그리고 혈소판 활성화 인자가 호중구에서 방출되어 고립된 토끼 폐에서 혈소판 매개 폐 부종을 유발한다(Samuelsson et al., 1987; Lamy et al., 1992; Zarbock and Ley, 2009).

본 연구에서 내 독소 혈증이 있는 토끼에서 폐의 W/D 비율의 증가, 및 조직학적 변화의 정도가 Omegaven에 의 해 감소되었다. 이러한 지표들은 혈관 내피 투과성 장애 로 인한 폐 부종의 지표이기 때문에 중요한 발견이다.

Huang, L. M. 등은 Omegaven이 급성 폐 손상이 있는 쥐 
에서 IL- $1 \beta$ 의 감소 및 폐포 상피 세포의 세포자연사를 줄 임으로써 염증반응을 약화시킴을 보고하였다(Huang et al., 2020). 이는 본 연구에서의 Omegaven의 항염증 효과와 일치하는 측면이 있다.

Mayer K 등은 경정맥 영양에서 오메가-3와 오메가-6 지 방 유제의 효과를 비교를 하였다. 오메가-6가 풍부한 지 방 유제를 준 그룹에서 더 높은 자유(free) 아라키돈 산 농도 및 호중구 기능 손상의 감소을 보고하여, 오메가-3 가 풍부한 지방 유제가 패혈증 환자에게서 더 이점이 있 을 것으로 주장하였다(Mayer et al., 2003). 이는 본 논문의 오메가-3가 풍부한 Omgeven이 오메가-6가 풍부한 Lipoven 보다 항염증 효과가 우월하다는 결과와 상통하는 측면이 있다.

Hall TC 등은 패혈증 중환자들 대상으로 오메가-3 지방 산이 풍부한 유제를 경정맥 통해 공급한 경우와 투여하 지 않은 경우를 비교하였으며, 이 비교에서 오메가-3 지 방산을 공급한 군에서 혈장 내 지질 성분의 개선을 볼 수 있었고, 이 결과가 환자의 생존율에 도움을 줄 수 있다고 보고하였다(Hall et al., 2016).

본 연구에서 Omegaven을 사용하지 않은 그룹에 비해 Omegaven을 사용한 그룹에서 BALF에서의 IL-8의 농도가 유의하게 낮았다. 이는 Omegaven이 BALF 내에서도 내독 소 혈증에 의한 사이토카인 반응을 억제하는 효과가 있 는 것으로 보인다. 이는 Omegaven이 사이토카인 반응 억 제를 통한 산소화 악화의 방지 및 폐 부종 약화에 효과가 있음을 시사하였다.

내독소 유발 폐 손상의 병태 생리는 복잡하고 이 손상 의 최종 단계는 활성화된 백혈구, 대식 세포들이 반응성 산소종, 프로테아제, 아라키돈 산 대사물의 방출로 폐의 내피 및 외피 세포의 손상, 높은 투과성에 의한 폐 부종이 라 생각된다. 다양한 염증성 매개체 및 사이토카인에 의 해 대식 세포, 중성구, 내피 세포 등을 활성화까지는 시 간이 필요하다. 그러므로 Omegaven의 초기의 투여가 이 최종 단계의 개입을 통해 폐 손상의 약화에 도움을 줄 수 있을 것으로 생각된다.

패혈증 및 패혈증성 쇼크에 의한 급성 호흡 곤란 증후 군이 있는 중환자들 상당수가 영양 불균형 및 영양 실조 를 겪고 있다. 이런 중환자들의 관리에서 가장 중요한 점 중 하나는 이 환자들에게 적절한 영양 공급을 해주는 것 이다. 패혈증 환자에게 적절한 영양 공급을 해주어야 한 다는 일치된 견해는 있지만 어떤 영양소 및 성분을 공급 해주어야 하는지에 대한 일치된 의견은 없다. Omegaven
의 공급이 패혈증에 의한 급성 호흡 곤란 증후군을 겪고 있는 환자에게서 항염증 효과를 거둘 수 있을 것으로 생 각된다. 그렇지만 급성 호흡 곤란 증후군을 가진 환자에 게서 장기간에 걸친 Omegaven 투여의 효과에 대한 연구 와 Omegaven의 적절한 용량을 결정하기 위한 추가적인 연구가 필요하다.

\section{ACKNOWLEDGEMENT}

None.

\section{CONFLICT OF INTEREST}

The authors have declared no conflict of interest.

\section{REFERENCES}

Allen TC, Kurdowska A. Interleukin 8 and acute lung injury. Arch Pathol Lab Med. 2014. 138: 266-269.

Augustsson K, Michaud DS, Rimm EB, Leitzmann MF, Stampfer MJ, Willett WC, Giovannucci E. A prospective study of intake of fish and marine fatty acids and prostate cancer. Cancer Epidemiol Biomarkers Prev. 2003. 12: 64-67.

Bernard C, Tedgui A. Cytokine network and the vessel wall. Insights into septic shock pathogenesis. Eur Cytokine Netw. 1992. 3: 19-33.

Bousquet M, Saint-Pierre M, Julien C, Salem N, Jr., Cicchetti F, Calon F. Beneficial effects of dietary omega-3 polyunsaturated fatty acid on toxin-induced neuronal degeneration in an animal model of parkinson's disease. FASEB J. 2008. 22: 1213-1225.

Brigham KL, Meyrick B. Endotoxin and lung injury. Am Rev Respir Dis. 1986. 133: 913-927.

Bucher HC, Hengstler P, Schindler C, Meier G. N-3 polyunsaturated fatty acids in coronary heart disease: A meta-analysis of randomized controlled trials. Am J Med. 2002. 112: 298-304.

Calder PC. Omega-3 fatty acids and inflammatory processes. Nutrients. 2010. 2: 355-374.

Calder PC. Omega-3 polyunsaturated fatty acids and inflammatory processes: Nutrition or pharmacology? Br J Clin Pharmacol. 2013. 75: 645-662.

Chollet-Martin S, Jourdain B, Gibert C, Elbim C, Chastre J, Gougerot-Pocidalo MA. Interactions between neutrophils and cytokines in blood and alveolar spaces during ards. Am J Respir Crit Care Med. 1996. 154: 594-601.

de Deckere EA. Possible beneficial effect of fish and fish n-3 polyunsaturated fatty acids in breast and colorectal cancer. 
Eur J Cancer Prev. 1999. 8: 213-221.

Demling RH. Adult respiratory distress syndrome: Current concepts. New Horiz. 1993. 1: 388-401.

Fortin PR, Lew RA, Liang MH, Wright EA, Beckett LA, Chalmers TC, Sperling RI. Validation of a meta-analysis: The effects of fish oil in rheumatoid arthritis. J Clin Epidemiol. 1995. 48: 1379-1390.

Goodman RB, Strieter RM, Martin DP, Steinberg KP, Milberg JA, Maunder RJ, Kunkel SL, Walz A, Hudson LD, Martin TR. Inflammatory cytokines in patients with persistence of the acute respiratory distress syndrome. Am J Respir Crit Care Med. 1996. 154: 602-611.

Green P, Hermesh H, Monselise A, Marom S, Presburger G, Weizman A. Red cell membrane omega-3 fatty acids are decreased in nondepressed patients with social anxiety disorder. Eur Neuropsychopharmacol. 2006. 16: 107-113.

Hall TC, Bilku DK, Neal CP, Cooke J, Fisk HL, Calder PC, Dennison AR. The impact of an omega-3 fatty acid rich lipid emulsion on fatty acid profiles in critically ill septic patients. Prostaglandins Leukot Essent Fatty Acids. 2016. 112: 1-11.

Huang LM, Hu Q, Huang X, Qian Y, Lai XH. Preconditioning rats with three lipid emulsions prior to acute lung injury affects cytokine production and cell apoptosis in the lung and liver. Lipids Health Dis. 2020. 19: 19.

Jacobs RF, Tabor DR, Burks AW, Campbell GD. Elevated interleukin-1 release by human alveolar macrophages during the adult respiratory distress syndrome. Am Rev Respir Dis. 1989. 140: 1686-1692.

Knaus WA, Sun X, Hakim RB, Wagner DP. Evaluation of definitions for adult respiratory distress syndrome. Am J Respir Crit Care Med. 1994. 150: 311-317.

Kollef MH, Schuster DP. The acute respiratory distress syndrome. N Engl J Med. 1995. 332: 27-37.

Lamy M, Deby-Dupont G, Deby C, Pincemail J, Duchateau J, Braun M, Damas P, Roth M. Measurements of mediator cascade during adult respiratory distress syndrome. In: Artigs A, Lemaire F, Suter PM, Zapol WM, Adult Respiratory Distress Syndrome. New York: Churchill Livingstone, 1992. 71-88.

Lewis RA, Austen KF, Soberman RJ. Leukotrienes and other products of the 5-lipoxygenase pathway. Biochemistry and relation to pathobiology in human diseases. N Engl J Med. 1990. 323: 645-655.

Maca J, Jor O, Holub M, Sklienka P, Bursa F, Burda M, Janout V, Sevcik P. Past and present ards mortality rates: A systematic review. Respir Care. 2017. 62: 113-122.
Maki KC, Orloff DG, Nicholls SJ, Dunbar RL, Roth EM, Curcio D, Johnson J, Kling D, Davidson MH. A highly bioavailable omega-3 free fatty acid formulation improves the cardiovascular risk profile in high-risk, statin-treated patients with residual hypertriglyceridemia (the esprit trial). Clin Ther. 2013. 35: 1400-1411, e1401-1403.

Mayer K, Fegbeutel C, Hattar K, Sibelius U, Kramer HJ, Heuer KU, Temmesfeld-Wollbruck B, Gokorsch S, Grimminger F, Seeger W. Omega-3 vs. Omega-6 lipid emulsions exert differential influence on neutrophils in septic shock patients: Impact on plasma fatty acids and lipid mediator generation. Intensive Care Med. 2003. 29: 1472-1481.

McCord JM, Gao B, Leff J, Flores SC. Neutrophil-generated free radicals: Possible mechanisms of injury in adult respiratory distress syndrome. Environ Health Perspect. 1994. 102 Suppl 10: 57-60.

Miller PE, Van Elswyk M, Alexander DD. Long-chain omega-3 fatty acids eicosapentaenoic acid and docosahexaenoic acid and blood pressure: A meta-analysis of randomized controlled trials. Am J Hypertens. 2014. 27: 885-896.

Naliwaiko K, Araujo RL, da Fonseca RV, Castilho JC, Andreatini R, Bellissimo MI, Oliveira BH, Martins EF, Curi R, Fernandes LC, Ferraz AC. Effects of fish oil on the central nervous system: A new potential antidepressant? Nutr Neurosci. 2004. 7: 91-99.

Okumura Y, Inoue H, Fujiyama Y, Bamba T. Effects of serine protease inhibitors on accumulation of polymorphonuclear leukocytes in the lung induced by acute pancreatitis in rats. J Gastroenterol. 1995. 30: 379-386.

Pignier C, Revenaz C, Rauly-Lestienne I, Cussac D, Delhon A, Gardette J, Le Grand B. Direct protective effects of polyunsaturated fatty acids, dha and epa, against activation of cardiac late sodium current: A mechanism for ischemia selectivity. Basic Res Cardiol. 2007. 102: 553-564.

Samuelsson B, Dahlen SE, Lindgren JA, Rouzer CA, Serhan CN. Leukotrienes and lipoxins: Structures, biosynthesis, and biological effects. Science. 1987. 237: 1171-1176.

Schmidt EB, Pedersen JO, Varming K, Ernst E, Jersild C, Grunnet N, Dyerberg J. N-3 fatty acids and leukocyte chemotaxis. Effects in hyperlipidemia and dose-response studies in healthy men. Arterioscler Thromb. 1991. 11: 429-435.

Sperling RI, Benincaso AI, Knoell CT, Larkin JK, Austen KF, Robinson DR. Dietary omega-3 polyunsaturated fatty acids inhibit phosphoinositide formation and chemotaxis in neutrophils. J Clin Invest. 1993. 91: 651-660. 
Suter PM, Suter S, Girardin E, Roux-Lombard P, Grau GE, Dayer

JM. High bronchoalveolar levels of tumor necrosis factor and its inhibitors, interleukin-1, interferon, and elastase, in patients with adult respiratory distress syndrome after trauma, shock, or sepsis. Am Rev Respir Dis. 1992. 145: 1016-1022.

Touqui L, Arbibe L. A role for phospholipase a2 in ards pathogenesis. Mol Med Today. 1999. 5: 244-249.

Wheeler AP, Bernard GR. Acute lung injury and the acute respiratory distress syndrome: A clinical review. Lancet. 2007. 369: 1553-1564.
Zarbock A, Ley K. The role of platelets in acute lung injury (ali) Frontiers in bioscience. 2009. 14: 150-158.

https://doi.org/10.15616/BSL.2021.27.1.19

Cite this article as: Jang EA, Son SK, Kang JH, Lee S, Kwak SH. Effects of Omega-3 Fatty Acid on Endotoxininduced Acute Lung Injury in Rabbits. Biomedical Science Letters. 2021. 27: 19-27. 